\title{
The Legacy of Oil Spills
}

\author{
J. T. Trevors • M. H. Saier Jr
}

Published online: 29 June 2010

C The Author(s) 2010. This article is published with open access at Springerlink.com

On April 20, 2010, an explosion occurred on a British Petroleum (BP) Deep Water Horizon platform, and 2 days later, the platform collapsed. Eleven workers were killed, and oil has been gushing out ever since. Although the initial reports were that about 50,000 gal were being released per day, every few weeks, the estimates released to the American public increased, until in early June, the company admitted that the actual rate has been and continues to be nearly 1 million gallons per day. It is now June, and oil continues to spew forth into the Gulf of Mexico, with BP telling us that no stoppage is possible until (maybe) August. Currently, about 45 miles of the Louisiana coast line are impacted, and it is feared that oil will spread until the coasts of Texas, Louisiana, Mississippi, Alabama, and Florida are seriously damaged. Even worse, it is possible that the oil will continue to move Northward, up the Eastern coast of the USA until most of the US Atlantic coast is affected. Because of the oil fires, the air pollution is

J. T. Trevors and M. H. Saier Jr authors are corresponding authors

J. T. Trevors $(\bowtie)$

School of Environmental Sciences, University of Guelph, Guelph, ON N1G 2W1, Canada

e-mail: jtrevors@uoguelph.ca

M. H. Saier Jr $(\bowtie)$

Division of Biological Sciences, University of California, La Jolla,

San Diego, CA 92093-0116, USA

e-mail:msaier@ucsd.edu tremendous, and no one has even begun to estimate the atmospheric damage; nor has it been possible to estimate the damage to marine life in the Gulf and beyond.

The 2010 hurricane season will soon be arriving, and hurricanes, if they occur as expected, may redistribute the oil over a much wider area, depending on the severity and course of the hurricane(s). A hurricane storm surge may transport the oil inland at ever increasing rates, depending on the track of the hurricane. Hurricanes can also move the oil away from the coast, again depending on the track taken. Regardless of where it goes, it is expected that the spill will impact marine life extensively, with several of the marine mammals and birds, recently rescued from the endangered species list, returning to this list. Published pictures of sea birds and mammals, including the beloved majestic pelicans, covered with crude oil, make the magnitude of the disaster apparent to anyone with access to these pictures.

The consequences of this disaster are far from realized, however. Seafood is being tested for oil contamination, and dead fish, sea birds and marine mammals are being washed up on the beaches. All recreational activities have come to a halt, and the tourist trade is expected to experience economic hardships for the coastal communities. Thus, the spill has disturbed the lifestyles of the people, the economy and the natural resources of several coastal states which will now require increased protection from ever increasing amounts of crude 
oil, long after the oil flow at this one platform has been halted. In addition, because of the commitment of the US government to war and excessive military expenditures, we do not have the funds to contribute to the effort, or even the funds required to provide the basic necessities of life to all American citizens.

What are the chances that another such disaster in the Gulf will occur in the near future? The odds are very high. There are 499 active oil platforms in the Western Planning Area, off the coast of Texas, and 3,359 active oil platforms in the Central Planning Area, off the coasts of Louisiana, Mississippi and Alabama. A major hurricane could cause damage to any one of these rigs comparable to the BP Deep Water Horizon disaster. Even without hurricanes, which are expected to increase in intensity with the warmer waters that accompany climate change, manmade disasters will continue to reign supreme. As in the case of the current BP platform disaster, when profits provide motivation rather than safety, you can expect more of same. As long as we continue to use gas and oil in large quantities, you can be sure that these disasters will continue to happen.

Few people are aware of the magnitudes of past oil spills. They are well aware of the Exxon Valdez disaster in Alaska, when the Valdez oil tanker hit an undersea reef and released about 10,000,000 gal. This one incident is well known because of the publicity it received, especially in the USA. The current Gulf of Mexico disaster is now estimated to have released roughly 30 million gallons as of June 1, 2010, three times that of the Valdez spill. However, the top ten oil spills were all worse than these. In 1991 in Kuwait, 520 million gallons were burnt, due to fires intentionally started when the Iraqi forces tried to prevent invasion by US troops. When a 1979 exploratory oil well blew out and leaked oil for one full year, 150 million gallons were released. When the tankers, the Atlantic Empress and the Aegean Captain, collided near Tobago in 1979, 90 million gallons were released. Other major disasters were due to pipeline leakage in Russia in 1994, costing 84 million gallons, the Persian Gulf Nowuz Field platform collapse, releasing 80 million gallons, and the fire on the Castillo de Bellver oil tanker, releasing 79 million gallons. Other major disasters were due to tankers running aground or exploding, or oil rigs exploding or burning. One thing is certain: as long as we continue to demand and use fossil fuels, such accidents will continue to occur. Each one of us who drives a motorized vehicle or uses electricity generated by the burning of fossil fuels, is responsible. There can be no finger pointing by any one of us.

As of June first, about one quarter of the Gulf of Mexico fisheries had been closed. These events are just as serious as they sound, and the forthcoming information to be released over the next several years and decades will document the seriousness of this one environmental calamity. However, to put the current situation into perspective, as noted above, the Gulf spill is just one of many disasters. The real cause, is not just the use of fossil fuels, but also that there are simply too many people in the world doing the wrong things. Wars, crimes against nature, irresponsibly high reproductive rates, pollution, and a lack of basic human rights in countries where the differential between the rich and the poor is excessive are all to blame.

Oil spills such as the current one leave a legacy for decades - maybe centuries - into the future. After all, the Gulf of Mexico already contains an immense dead zone. It is likely that far more fisheries will be forced to close due both to the death of fish, and because the ones that survive will be contaminated. The deaths of marine animals and migratory birds and the impact of their losses on marine ecosystems cannot be evaluated. The presence of submerged oil dispersed throughout unknown locations will have further consequences probably for decades all because of our addiction for oil and our excessive numbers, and no one can evaluate the human health effects of such disasters, initially for response personnel, but later for everyone living near the Gulf coast.

A faster transition away from fossil fuels and towards alternative energy sources will be required to avoid these reoccurring incidents. Clean-up efforts will require decades of dedicated work. A toxic environment cannot be converted to a healthy one without time, money and sweat. Reconstruction of wetlands is not likely to be possible, maybe ever, and if so, it may require a lot of expensive scientific research and risk assessment. There seems to be no alternative but to improve environmental legislation, a consequence of our ever increasing population of demanding and greedy people. Yes, greed, an unfortunate element of human nature, can be counted as one of the forces that will restrict our personal freedoms as we squander away our precious irreplaceable resources. 
The consequences of oil spills is not the type of legacy one human generation should pass on to the next. Being addicted to oil directly causes spills as well as global climate change. There are simply too many humans doing the wrong things in the world. Correct knowledge and its implementation is an immense part of the solution to humanity's sustainable future. Let us leave some honorable legacies to our offspring such as peace, cooperation, a sustainable human population, and the provision of basic human rights. G8 and G20 summits generally do not deal with solutions to interconnected problems, e.g., between the environment and economics. Instead, under the guise of democratic rhetoric, they pretend to meet the needs of the countries they represent. They are not people's summits, but simply summits without democratic agendas and outcomes. The legacy that nondemocratic summits and economic systems implement represent the mistaken policies that spell failure. When economics destroys environments, there is no hope for the future.

Open Access This article is distributed under the terms of the Creative Commons Attribution Noncommercial License which permits any noncommercial use, distribution, and reproduction in any medium, provided the original author(s) and source are credited. 